\title{
Uptake of evidence by physicians: De- adoption of erythropoiesis-stimulating agents after the TREAT trial
}

\author{
Khoa Vu' ${ }^{1}$ Jiani Zhou ${ }^{2}$, Alexander Everhart ${ }^{2}$, Nihar Desai ${ }^{3}$, Jeph Herrin ${ }^{4}$, Anupam B. Jena ${ }^{5}$, Joseph S. Ross ${ }^{6}$,
} Nilay D. Shah ${ }^{7}$ and Pinar Karaca-Mandic ${ }^{8^{*}}$ (i)

\begin{abstract}
Background: Variation in de-adoption of ineffective or unsafe treatments is not well-understood. We examined deadoption of erythropoiesis-stimulating agents (ESA) in anemia treatment among patients with chronic kidney disease (CKD) following new clinical evidence of harm and ineffectiveness (the TREAT trial) and the FDA's revision of its safety warning.

Method: We used a segmented regression approach to estimate changes in use of epoetin alfa (EPO) and darbepoetin alfa (DPO) in the commercial, Medicare Advantage (MA) and Medicare fee-for-service (FFS) populations. We also examined how changes in both trends and levels of use were associated with physicians' characteristics.

Results: Use of DPO and EPO declined over the study period. There were no consistent changes in DPO trend across insurance groups, but the level of DPO use decreased right after the FDA revision in all groups. The decline in EPO use trend was faster after the TREAT trial for all groups. Nephrologists were largely more responsive to evidence than primary care physicians. Differences by physician's gender, and age were not consistent across insurance populations and types of ESA.
\end{abstract}

Conclusions: Physician specialty has a dominant role in prescribing decision, and that specializations with higher use of treatment (nephrologists) were more responsive to new evidence of unsafety and ineffectiveness.

Keywords: De-adoption, Physician prescribing, Medication utilization, Medical safety

\section{Background}

Anemia is common among patients with chronic kidney disease (CKD), and erythropoiesis-stimulating agents (ESA) are commonly used to stimulate bone marrow to produce red blood cells, improving anemia symptoms and preventing the need for blood transfusion [1]. The treatment is typically initiated when a patient's level of hemoglobin concentration is too low, and the treatment is used until the hemoglobin concentration reaches a

\footnotetext{
* Correspondence: pkmandic@umn.edu

${ }^{8}$ National Bureau of Economic Research and OptumLabs Visiting Fellow, University of Minnesota Carlson School of Management, 321 19th Avenue South, Minneapolis, MN 55455, USA

Full list of author information is available at the end of the article
}

"safe" range [2]. The main types of ESA in the U.S. are epoetin alfa (EPO) [1] and darbepoetin alfa (DPO) [3], which mainly differ in how frequently the drug is administered to patients [2]. DPO is a newer, synthetic form of naturally-occurring erythropoietin that has a longer duration of action, requiring less frequent administration [4]. EPO is usually administered three times a week while DPO is administered once a week up to once every a month $[5,6]$.

The use of ESA therapy for anemia in CKD patients is common in many countries - Wong et al. [7] estimated that $48 \%$ patients with a hemoglobin level $<10 \mathrm{~g} / \mathrm{dL}$ in the US, $58 \%$ in Brazil, $66 \%$ in France, and $70 \%$ in Germany were prescribed an ESA or iron in the 3

C C The Author(s). 2021 Open Access This article is licensed under a Creative Commons Attribution 4.0 International License, which permits use, sharing, adaptation, distribution and reproduction in any medium or format, as long as you give appropriate credit to the original author(s) and the source, provide a link to the Creative Commons licence, and indicate if changes were made. The images or other third party material in this article are included in the article's Creative Commons licence, unless indicated otherwise in a credit line to the material. If material is not included in the article's Creative Commons licence and your intended use is not permitted by statutory regulation or exceeds the permitted use, you will need to obtain permission directly from the copyright holder. To view a copy of this licence, visit http://creativecommons.org/licenses/by/4.0/ The Creative Commons Public Domain Dedication waiver (http://creativecommons.org/publicdomain/zero/1.0/) applies to the data made available in this article, unless otherwise stated in a credit line to the data. 
months following $\mathrm{Hb}$ measurement. Clinical evidence over the past decades, however, has suggested that using ESA to target high hemoglobin levels (i.e., $\geq 13 \mathrm{~g} / \mathrm{dL}$ ) might be unsafe. The first study to raise safety concerns was the Normal Hematocrit Cardiac Trial (NHCT) [8] in hemodialysis patients in 1998 (targeting 14 versus 10 $\mathrm{g} / \mathrm{dL}$ ), followed by two other studies in patients with non-dialysis CKD in 2006 - the Correction of Hemoglobin and Outcomes in Renal Insuggeiciency [9] (CHOIR; targeting 13.5 versus $11.3 \mathrm{~g} / \mathrm{dL}$ ) and Cardiovascular Risk Reduction by Early Anemia Treatment with Epoetin beta [10] (CREATE; targeting $13.5 \mathrm{~g} / \mathrm{dL}$ versus $11.5 \mathrm{~g} / \mathrm{dL}$ ). In October 2009, the Trial to Reduce Cardiovascular Events with Aranesp Therapy (TREAT), a large placebo-controlled study, found that DPO treatment targeting a hemoglobin level of $13 \mathrm{~g} / \mathrm{dL}$ did not reduce the risk of either death, cardiovascular, or renal events, but resulted in a higher risk of stroke and less frequent cardiac revascularization, compared to using DPO when hemoglobin level fell below $9 \mathrm{~g} / \mathrm{dL}$ [11]. In response, the U.S. Food and Drug Administration (FDA) revised its original black-box warnings in June 2011, recommending using the lowest dose of ESA necessary to reduce the need for blood transfusion, and reducing dose or interrupting the treatment when $\mathrm{Hb}$ level exceeds $10 \mathrm{~g} / \mathrm{dL}$ [12]. Other health authorities and organizations in the U.S. and other countries have also adjusted practice guidelines to reflect this risk or changed the payment rules regarding ESA treatment [13-17].

Several prior studies have found substantial deadoption of ESA treatment in the US following the CREATE and CHOIR publications $[18,19]$, the TREAT trial $[20,21]$, the FDA revision [21], and the change of payment rules $[22,23]$. Other studies have also documented decreases of ESA treatment during the same period in other countries such as Canada, Germany, and Japan $[17,24]$. These studies have not examined physician patterns of de-adopting ESA treatment, nor whether these patterns differed by insurance type. If certain types of physicians or certain pharmacy plans were associated with lower rates of de-adoption, the information could guide efforts to reduce the use of ineffective and unsafe treatments. Moreover, none of these studies separated the impact of the evidence on the use of different types of ESA. The decisions to prescribe EPO or DPO are likely influenced by various factors such as availability, cost, and patient preference $[25,26]$. Additionally, while the TREAT trial was studied DPO, the FDA revision applied to both types of ESA, and it is plausible that the impact of the TREAT evidence differentially affected EPO and DPO prescribing.

Using administrative claims data in the US, we examined de-adoption of ESA treatment among advanced CKD stages 3-5, non-dialysis patients - those who are more likely to have anemia relative to patients in early stages of the disease [27]. First, we examined changes of EPO separately from that of DPO. Second, we examined which physician characteristics were associated with deadoption, examining changes in prescribing in both levels and trends in response to both the trial and the FDA revision. We separately examined de-adoption in three insurance populations: commercially insured, Medicare Advantage (MA), and Medicare Fee-forService (FFS).

In the context of U.S. healthcare, it is crucial to consider different insurance types because of their differences in reimbursement policies and demographic characteristics. The Medicare program is the primary source of healthcare insurance for individuals aged 65 and above, while commercially insured individuals are typically younger. Within the Medicare program, enrollees may receive insurance through Medicare FFS (also known as traditional Medicare) or through Medicare Advantage. In Medicare FFS, healthcare providers bill the U.S. Centers for Medicare and Medicaid Services directly for any care that is provided. Medicare Advantage is Medicare plans offered by commercial insurance companies that contract with Medicare to provide coverage for inpatient and outpatient services as well as prescription drugs.

\section{Methods}

\section{Data source}

We used administrative claims data from two sources. The first source was the 2007-2015 commercial and MA administrative claims from the OptumLabs ${ }^{\circ}$ Data Warehouse (OLDW), a comprehensive, longitudinal, real-world data asset with de-identified claims and clinical information [28]. The second source was a $20 \%$ random sample of Medicare FFS beneficiaries from 2007 to 2013. We combined the administrative data with information about physicians from Doximity ${ }^{\circ}$. Doximity is a data resource that allowed us to observe key physician characteristics. This database includes information from a wide range of sources, such as the National Provider Identifier Registry and state medical boards, and has been validated and used in previous literature [29-32].

\section{Study population}

We identified three separate cohorts of patients who had at least one claim for CKD diagnosis (based on ICD 9$\mathrm{CM}$ and ICD 10-CM diagnosis codes) anytime between $1 / 2007$ and $12 / 2015$; all were identified using medical claims in either commercial, MA or FFS data sources. We restricted the cohorts to those who had continuous medical and prescription drug coverage for the 12 months before the index diagnosis claim for CKD. In any given month, we flagged a patient to have CKD if 
they had at least one inpatient claim or two outpatient claims spaced more than 30 days apart with CKD diagnosis in the past 6 months. Our final analytic samples consisted of the patient-months identified to have CKD stages 3-5 without dialysis treatment. Supplemental Digital Content (Additional file 1), Section 1 provides details on the ICD 9-CM and ICD 10-CM diagnosis codes and CPT codes used to identify the study sample.

\section{Physician assignment}

To analyze changes in ESA use by physician characteristics, we attributed each patient-month observation to the physician responsible for making decisions concerning the ESA treatment following a 2-step procedure. In the first step, we isolated medical claims for all evaluation and management (E\&M) visits for each patientmonth observation and divided claims into four categories based on the specialty of the associated physician: (1) nephrology, (2) internist, (3) hematology and oncology, and (4) all others. Drawing from the literature [33], we ranked these categories based on relevance to anemia treatment for patients with CKD with (1) being the most relevant and (4) being the least relevant specialty. For example, even if an internist had more E\&M claims than a nephrologist in a given month, the nephrologist was attributed to the patient-month. Within each specialty category, the physician with the most E\&M visits was attributed to the patient-month (ties were assigned randomly); and we carried forward that attribution, month after month, until an interruption in patient-months at risk or a change in physician with the most visits. Once each patient-month observation was attributed to a physician, we used the National Physician Identification (NPI) to merge in physician characteristics from the Doximity ${ }^{\bullet}$ database.

\section{Measures}

The two outcome variables were dichotomous indicators for DPO and EPO use in a given patient-month observation (unit of analysis). The indicators were constructed by identifying ESA administration in outpatient claims (CPT codes "J0881" (Darbepoetin Alfa) and "J0885" (Epoetin Alfa)) or in pharmacy claims.

Patient covariates included sex, age, CKD stage, and Elixhauser comorbidity index. Physician characteristics included sex, specialty, and age $(<50,50$ or older), and physician specialty (primary care physicians (PCPs), nephrologists, and non-nephrology specialists, including internists, hematologists, and oncologists).

\section{Statistical analysis}

We summarized DPO and EPO use, patient and physician characteristics, reporting mean (SD) or $\mathrm{n}(\%)$ according the characteristic. Then, to assess patterns of de-adoption we estimated a series of linear segmented regression models with panel data [34-36]. First, we examined changes in ESA use among CKD patients after new evidence of unsafety and ineffectiveness from the TREAT trial publication (10/2009) and the FDA revision $(6 / 2011)$. We considered three time-periods based on these events:

- Baseline period (pre-TREAT): 1/2007 (start) to 6/ 2009

- Period 1 (post-TREAT/pre-FDA): $2 / 2010$ to $2 / 2011$

- Period 2 (post-TREAT/post-FDA): 10/2011 to 12/ 2015 (end)

We excluded the three-month periods before and after each event to avoid capturing any anticipatory or short term effects [36]. We estimated changes in the level and the trend in use of DPO and EPO use in period 1 relative to the baseline, as well as in period 2 relative to period 1. All models adjusted for patient and physician characteristics and included calendar month dummy variables to account for seasonality. Standard errors were clustered at the patient level. Models were estimated separately for commercially insured, MA, and Medicare FFS cohorts. These models let us assess whether there were differences in de-adoption by payer; though data use agreements precluded combining these cohorts for formal testing, we report the effect magnitudes and $P$ values for each. Then, to assess whether de-adoption (changes in levels or trends) differed by physician characteristics, we estimated a second set of models which included interactions of the levels and trends with physician characteristics one at a time (for example, nephrologist or non-nephrologist). Details of the model specifications are provided in Supplemental Digital Content (Additional file 1), Section 2.

All analyses were performed with SAS, Version 9.4 (Copyright@ $2002-2012$ SAS Institute Inc.) and Stata 14.2 (StataCorp, College Station, TX). The study was deemed exempt from review by the University of Minnesota Institutional Review Board because the data were de-identified.

\section{Results}

Our study included 501,287 patient-month observations for the commercially insured, 1,206,050 for MA, and $8,106,600$ for Medicare FFS. Unadjusted rates of DPO use were 5.3, 3.2 and $3.5 \%$ for each insurance group respectively, while corresponding unadjusted rates of EPO use were 7.2, 5.3 and $4.5 \%$ (Table 1). For the commercially insured, the mean (SD) age was 61.7 (13.1) and the mean Elixhauser comorbidity index was 6.1 (3.0). For MA and Medicare FFS samples, the mean ages were 75.2 (8.0) and 76.3 (9.7), and the mean comorbidity 
Table 1 Patients with Chronic Kidney Disease (CKD) stages 3-5

\begin{tabular}{|c|c|c|c|}
\hline & $\begin{array}{l}\text { Commercial } \\
(N=501,287)\end{array}$ & $\begin{array}{l}\text { Medicare Advantage } \\
(N=1,206,050)\end{array}$ & $\begin{array}{l}\text { Medicare FFS } \\
(N=8,106,600)\end{array}$ \\
\hline \multicolumn{4}{|l|}{ ESA use } \\
\hline EPO use (\%) & 7.2 & 5.3 & 4.5 \\
\hline DPO use (\%) & 5.3 & 3.2 & 3.5 \\
\hline \multicolumn{4}{|l|}{ Patient characteristics } \\
\hline Female (\%) & 42.9 & 53.1 & 50.9 \\
\hline Mean Age (SD) & $61.7(13.1)$ & $75.2(8.0)$ & $76.3(9.7)$ \\
\hline Mean Elixhauser score (SD) & $6.1(3.0)$ & $7.2(3.1)$ & $14.9(10.2)$ \\
\hline CKD stage $3(\%)$ & 75.3 & 76.0 & 75.8 \\
\hline CKD stage $4(\%)$ & 21.5 & 21.8 & 19.9 \\
\hline CKD stage 5 (\%) & 3.2 & 2.2 & 4.3 \\
\hline \multicolumn{4}{|l|}{ Physician characteristics } \\
\hline Female (\%) & 19.3 & 19.8 & 17.1 \\
\hline Completed residency under 20 years ago (\%) & 55.0 & 53.7 & \\
\hline Under 50 years old (\%) & 47.2 & 45.6 & 39.9 \\
\hline Nephrologist (\%) & 63.2 & 46.1 & 24.3 \\
\hline Internist (\%) & 11.2 & 22.2 & 27.7 \\
\hline Hematologist (\%) & 2.5 & 2.2 & 4.8 \\
\hline Other specialties & 25.5 & 32.2 & 43.2 \\
\hline Number of unique patients & 116,968 & 227,145 & 765,159 \\
\hline Number of unique physicians & 46,033 & 56,517 & 302,543 \\
\hline
\end{tabular}

index was 7.2 (3.1) and 14.9 (10.2), respectively. CKD stage 3 was the most prevalent in all three samples $(75.3$ to $76.0 \%)$. The majority of the observations for the commercially insured and MA patients were attributed to nephrologists (63.2 and $46.1 \%$, respectively), while only $24.3 \%$ of the Medicare FFS observations were attributed nephrologists.

For all three cohorts, unadjusted rates of EPO and DPO use were declining before the TREAT trial and over the entire study period (Fig. 1). For example, among the commercially insured, EPO use was $16 \%$ and DPO use was $12 \%$ in January 2007, while corresponding rates were 10 and $8 \%$ in September 2009, just before the TREAT trial.

\section{Changes in levels and trends of use over time by insurance cohort \\ DPO (Table 2, panel a)}

Prior to the TREAT trial, DPO use declined by an average of 0.13 percentage points per month in each insurance group (all $P$-values $<0.001$ ). Following the trial publication, commercially insured and MA did not have immediate changes in levels of use, but Medicare FFS had an immediate increase in levels of use $(P$-value $<$ $0.01)$. The rate of decline among commercially insured and Medicare FFS patients had decreased (i.e, a less negative trend following trial publication), while the rate of decline for MA patients did not change. After the FDA revised its black box warning, there was an immediate decline in the levels of DPO use in all 3 groups (all $P$-values $<0.05)$. Commercially insured patients experienced no changes in trends, while MA and FFS patients experienced decreases in rates of decline in use (both $P$ values <0.005).

\section{EPO (Table 2, panel B)}

Before the TREAT trial publication, EPO use was decreasing for commercial and Medicare FFS patients (both, $P$ values $<0.001$ ), but was flat for MA patients. After the publication, there was no change in levels for commercially insured and MA but an increase in level for Medicare FFS $(P<0.001)$. EPO trends decreased further for all three cohorts (all $P$-values $<0.001$ ). Following the FDA revision, MA and FFS patients experienced a decrease in levels (both $P$-values $<0.05$ ), and all patient groups experienced an increase in trends (all $P$-values $<0.005$ ).

\section{Changes in trends and levels of use over time by physician characteristics DPO (Table 3)}

In commercial and MA groups, we found no significant differences in changes of DPO trends between PCPs and 


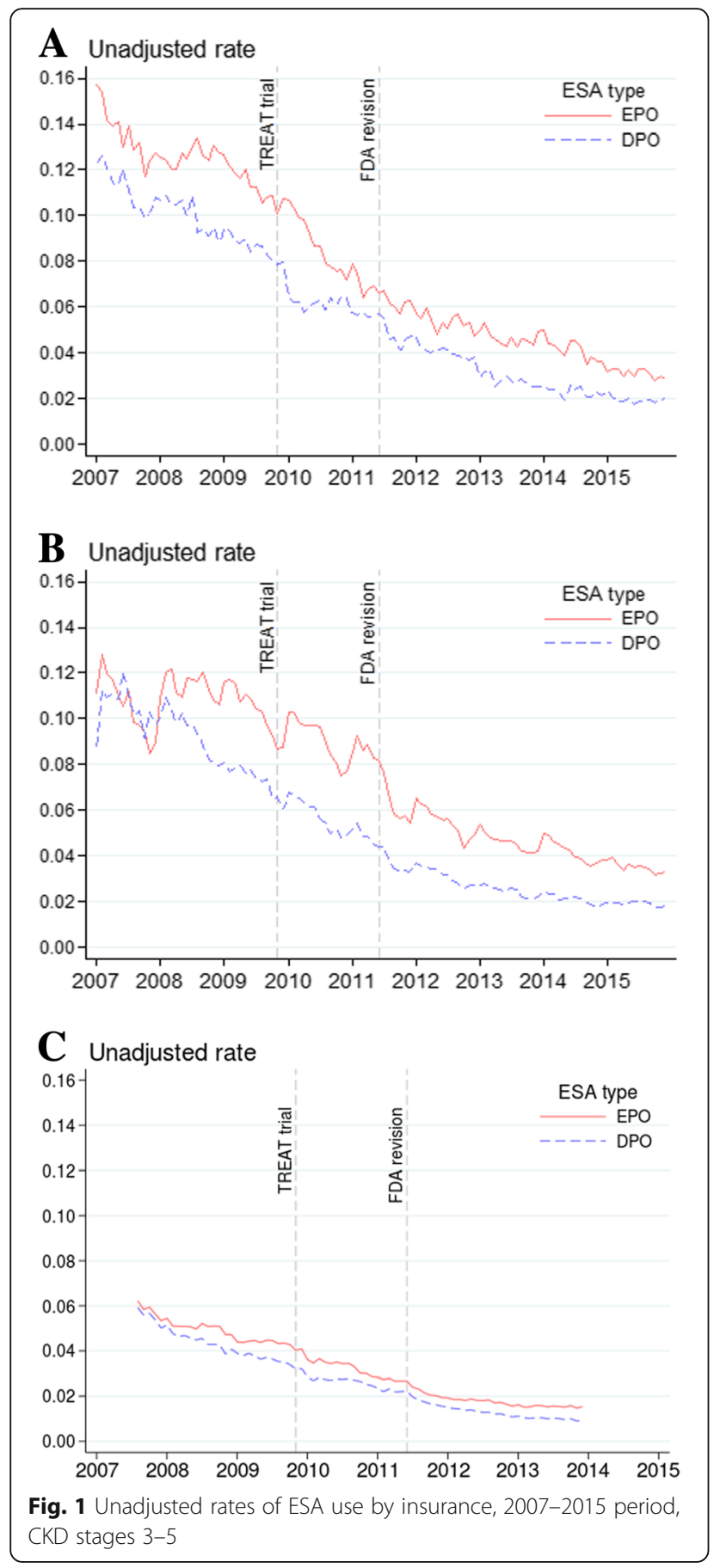

nephrologists following the TREAT trial publication and the FDA revision. In the commercial group, decreases in level of DPO use immediately following the FDA revision were larger among nephrologists relative to PCPs $(P$-value $=0.05)$. In Medicare FFS, we observed that nephrologists experienced a larger immediate increase in DPO use levels $(P$-value $<0.05)$ after the trial and a larger increase of monthly trends after the FDA revision $(P$-value $<0.05)$ compared to the PCPs.
In the commercial group, increases of monthly trends of DPO use were smaller for female physicians compared to male physicians after the TREAT trial ( $P$-value $<0.01)$. DPO trends decreased after the FDA revision, but the decreases of monthly trends of DPO use were smaller for female physicians than male physicians $(P$ value $<0.05)$. In the MA group, increases of monthly trends of DPO use after the trial publication were also smaller among female physicians relative to male physicians $(P$-value $<0.05)$. Level of DPO use decreased immediately following the FDA revision, but female physicians exhibited a smaller decrease (i.e. the decrease was less negative) compared to male physicians ( $P$-value $<0.05$ ). Monthly trends of DPO use increased more for female physicians than male physicians after the FDA revision $(P$-value $<0.05)$. In contrast, there were no significant differences in changes of levels or trends between male and female physicians in the Medicare FFS group following the two events.

We did not observe any significant differences in changes of levels and trends between physicians under and over 50 years old following the two events in the commercial group. In contrast, we found that physicians under 50 years old in the MA group exhibited a smaller immediate decrease (i.e. the decrease was less negative) in DPO prescribing following the trial $(P$-value $<0.01)$ and the FDA revision $(P$-value $<0.05)$ compared to older physicians. In the Medicare FFS group, physicians under 50 years old experienced a larger decrease in DPO trends following the trial $(P$-value $<0.05)$ and a larger increase of DPO trends following the revision $(P$-value $<0.05)$ compared to physicians over 50 years old.

\section{EPO (Table 4)}

Immediate changes of EPO levels following the TREAT trial publication and the FDA revision were not significantly different between nephrologists versus PCPs in all three insurance groups. In the MA and Medicare FFS cohorts, monthly EPO trends increases following the FDA revision were larger for nephrologists ( $P$-value $<0.05)$.

Similarly, there were no significant differences between male and female physicians in immediate changes of EPO levels following the TREAT trial and the FDA revision in all three insurance groups. Changes of monthly trends after the two events were not significantly different between the female and male physicians except for the MA group, where EPO trends decreased after the TREAT trial, but the decrease was smaller (i.e. less negative) for female physicians relative to male physicians $(P$-value $<0.05)$.

Immediate changes in EPO levels and monthly trends following the trial and the FDA revision were also not significantly different between physicians under and over 
Table 2 Adjusted changes in EPO and DPO rates in levels and trends following the TREAT trial publication and the FDA warning revision

\begin{tabular}{|c|c|c|c|c|c|c|c|c|}
\hline \multicolumn{3}{|c|}{ Commercial } & \multicolumn{3}{|c|}{ Medicare Advantage } & \multicolumn{3}{|c|}{ Medicare FFS } \\
\hline \multirow{3}{*}{$\begin{array}{l}\text { Baseline } \\
\text { trend }\end{array}$} & Changes & & \multirow{3}{*}{$\begin{array}{l}\text { Baseline } \\
\text { trend }\end{array}$} & Changes & & \multirow{3}{*}{$\begin{array}{l}\text { Baseline } \\
\text { trend }\end{array}$} & \multirow{2}{*}{\multicolumn{2}{|c|}{$\frac{\text { Changes from }}{\text { previous period }}$}} \\
\hline & \multicolumn{2}{|c|}{ previous period } & & \multicolumn{2}{|c|}{ previous period } & & & \\
\hline & Period 1 & Period 2 & & Period 1 & Period 2 & & Period 1 & Period 2 \\
\hline (1) & (2) & (3) & (4) & (5) & (6) & (7) & (8) & (9) \\
\hline
\end{tabular}

\begin{tabular}{|c|c|c|c|c|c|c|c|c|c|}
\hline \multicolumn{10}{|c|}{ Panel A: DPO use } \\
\hline \multirow[t]{3}{*}{ Trends } & -0.13 & 0.10 & -0.02 & -0.13 & 0.02 & 0.08 & -0.13 & 0.07 & 0.03 \\
\hline & $(-0.17,-0.09)$ & $(0.02,0.17)$ & $(-0.09,0.04)$ & $(-0.2,-0.09)$ & $(-0.05,0.09)$ & $(0.03,0.13)$ & $(-0.13,-0.11)$ & $(0.05,0.08)$ & $(0.01,0.004)$ \\
\hline & {$[<0.001]$} & {$[0.010]$} & {$[0.478]$} & {$[<0.001]$} & {$[0.633]$} & {$[0.003]$} & {$[<0.001]$} & {$[<0.001]$} & {$[<0.001]$} \\
\hline \multirow[t]{3}{*}{ Levels } & & -0.85 & -1.33 & & -0.245 & -0.66 & & 0.61 & -0.60 \\
\hline & & $(-1.74,0.03)$ & $(-2.2,-0.05)$ & & $(-1.11,0.62)$ & $(-1.28,-0.03)$ & & $(0.45,0.77)$ & $(-0.77,-0.48$ \\
\hline & & {$[0.061]$} & {$[0.003]$} & & {$[0.581]$} & {$[0.040]$} & & {$[<0.001]$} & {$[<0.001]$} \\
\hline \multicolumn{10}{|c|}{ Panel B: EPO use } \\
\hline \multirow[t]{3}{*}{ Trends } & -0.07 & -0.18 & 0.19 & -0.003 & -0.17 & 0.11 & -0.07 & -0.03 & 0.10 \\
\hline & $(-0.1,-0.03)$ & $(-0.27,-0.09)$ & $(0.11,0.26)$ & $(-0.05,0.04)$ & $(-0.24,-0.09)$ & $(0.05,0.17)$ & $(-0.08,-0.07)$ & $(-0.05,-0.02)$ & $(0.08,0.11)$ \\
\hline & {$[0.001]$} & {$[<0.001]$} & {$[<0.001]$} & [0.913] & {$[<0.001]$} & {$[0.001]$} & {$[<0.001]$} & {$[<0.001]$} & {$[<0.001]$} \\
\hline \multirow[t]{3}{*}{ Levels } & & -0.62 & 0.61 & & -0.80 & -0.87 & & 0.32 & -0.18 \\
\hline & & $(-1.63,0.39)$ & $(-0.36,1.58)$ & & $(-1.78,0.18)$ & $(-1.65,-0.09)$ & & $(0.15,0.49)$ & $(-0.3,-0.01)$ \\
\hline & & {$[0.228]$} & {$[0.215]$} & & {$[0.110]$} & {$[0.028]$} & & {$[<0.001]$} & {$[0.034]$} \\
\hline Observations & 382,608 & & & 960,846 & & & $6,638,950$ & & \\
\hline
\end{tabular}

Estimates are reported for baseline trends and changes of trends and levels of DPO and EPO use, compared to previous periods. Baseline refers to the period between Jan-2007 to June-2009; period 1 (post-TREAT/pre-FDA) is between Feb-2010 and Feb-2011; period 2 (post-TREAT/post-FDA) is between Oct-2011 and Dec-2015. All estimates were multiplied with 100 to represent percentage point changes. All samples consist of patients with CKD stage 3 to 5 . All models control for patients' sex and age and physicians' specialty, age, sex, and experience (see text for details). Standard errors are clustered at the patient level; $95 \%$ confidence interval is reported in parentheses, and $p$-value is reported in brackets

Table 3 Changes in DPO use levels and trends by physician characteristics

\begin{tabular}{|c|c|c|c|c|c|c|c|c|c|c|c|}
\hline \multicolumn{4}{|c|}{ Commercial } & \multicolumn{4}{|c|}{ Medicare Advantage } & \multicolumn{4}{|c|}{ Medicare FFS } \\
\hline \multicolumn{2}{|c|}{$\begin{array}{l}\text { Change from } \\
\text { baseline to Period } 1\end{array}$} & \multicolumn{2}{|c|}{$\begin{array}{l}\text { Change from Period } 1 \\
\text { to } 2\end{array}$} & \multicolumn{2}{|c|}{$\begin{array}{l}\text { Change from baseline } \\
\text { to Period } 1\end{array}$} & \multicolumn{2}{|c|}{$\begin{array}{l}\text { Change from Period } \\
1 \text { to } 2\end{array}$} & \multicolumn{2}{|c|}{$\begin{array}{l}\text { Change from baseline } \\
\text { to Period } 1\end{array}$} & \multicolumn{2}{|c|}{$\begin{array}{l}\text { Change from Period } \\
1 \text { to } 2\end{array}$} \\
\hline Trends & Levels & Trends & Levels & Trends & Levels & Trends & Levels & Trends & Levels & Trends & Levels \\
\hline (1) & (2) & (3) & (4) & (5) & (6) & (7) & (8) & (9) & (10) & (11) & (12) \\
\hline
\end{tabular}

Panel A: Nephrologists relative to PCPs (reference)

$\begin{array}{rllllllllllll}\text { Difference } & 0.12 & 1.06 & -0.10 & -1.96 & 0.13 & 0.62 & 0.06 & 0.44 & 0.02 & 0.48 & 0.03 & 0.21 \\ & (-0.06, & (-1.45, & (-0.26, & (-3.91, & (0.00,0.26) & (-0.96, & (-0.05, & (-0.91, & (-0.01, & (0.02,0.74) & (0.003, & (-0.13, \\ 0.31) & 3.57) & 0.06) & 0.00) & & 2.21) & 0.16) & 1.80) & 0.06) & 0.06) & 0.56) \\ {[0.189]} & {[0.407]} & {[0.220]} & {[0.050]} & {[0.057]} & {[0.442]} & {[0.287]} & {[0.523]} & {[0.127]} & {[0.040]} & {[0.027]} & {[0.230]}\end{array}$

Panel B: Female physicians relative to male physicians (reference)

\begin{tabular}{|c|c|c|c|c|c|c|c|c|c|c|c|c|}
\hline \multirow[t]{3}{*}{ Difference } & -0.23 & -0.70 & 0.16 & 1.93 & -0.21 & -0.62 & 0.14 & 1.65 & -0.01 & -0.07 & -0.01 & -0.24 \\
\hline & $\begin{array}{l}(-0.40 \\
-0.62)\end{array}$ & $\begin{array}{l}(-2.77 \\
1.38)\end{array}$ & $(0.02,0.31)$ & $\begin{array}{l}(-0.60 \\
3.91)\end{array}$ & $\begin{array}{l}(-0.38 \\
-0.03)\end{array}$ & $\begin{array}{l}(-2.79 \\
1.55)\end{array}$ & $(0.01,0.27)$ & $(0.06,3.25)$ & $\begin{array}{l}(-0.04 \\
0.02)\end{array}$ & $\begin{array}{l}(-0.44 \\
0.30)\end{array}$ & $\begin{array}{l}(-0.03, \\
0.02)\end{array}$ & $\begin{array}{l}(-0.58, \\
0.11)\end{array}$ \\
\hline & {$[0.007]$} & {$[0.512]$} & {$[0.030]$} & {$[0.057]$} & {$[0.020]$} & {$[0.573]$} & {$[0.032]$} & {$[0.042]$} & {$[0.602]$} & {$[0.724]$} & {$[0.667]$} & {$[0.180]$} \\
\hline \multicolumn{13}{|c|}{ anel C: Physicians under 50 years old relative to physicians over 50 years old (reference) } \\
\hline \multirow[t]{3}{*}{ Difference } & 0.09 & 0.40 & -0.03 & -0.53 & 0.02 & 2.51 & 0.09 & 1.45 & -0.03 & 0.003 & 0.02 & 0.11 \\
\hline & $\begin{array}{l}(-0.05 \\
0.24)\end{array}$ & $\begin{array}{l}(-1.32 \\
2.13)\end{array}$ & $\begin{array}{l}(-0.16 \\
0.10)\end{array}$ & $\begin{array}{l}(-2.31 \\
1.26)\end{array}$ & $\begin{array}{l}(-0.12 \\
0.16)\end{array}$ & $(0.79,4.22)$ & $\begin{array}{l}(-0.02 \\
0.19)\end{array}$ & $(0.14,2.76)$ & $\begin{array}{l}(-0.05 \\
-0.002)\end{array}$ & $\begin{array}{l}(-0.28 \\
0.29)\end{array}$ & $\begin{array}{l}(0.0003, \\
0.04)\end{array}$ & $\begin{array}{l}(-0.16 \text {, } \\
0.38)\end{array}$ \\
\hline & {$[0.218]$} & {$[0.647]$} & {$[0.627]$} & {$[0.564]$} & {$[0.744]$} & {$[0.004]$} & {$[0.105]$} & [0.031] & {$[0.037]$} & [0.983] & {$[0.047]$} & [0.415] \\
\hline
\end{tabular}

Estimates are reported for changes of trends and levels of DPO use (compared to previous periods) by physician's characteristics as well as P-value for differences across physician characteristics. Baseline refers to the period between Jan-2007 to June-2009; period 1 (post-TREAT/pre-FDA) is between Feb-2010 and Feb-2011; period 2 (post-TREAT/post-FDA) is between Oct-2011 and Dec-2015. All estimates were multiplied with 100 to represent percentage point changes. All samples consist of patients with CKD stage 3 to 5 . All models control for patients' sex and age and physicians' specialty, age, sex, and experience (see text for details). Standard errors are clustered at the patient level; $95 \%$ confidence interval is reported in parentheses, and $P$-value is reported in brackets 
Table 4 Changes in EPO use levels and trends by physician characteristics

\begin{tabular}{|c|c|c|c|c|c|c|c|c|c|c|c|}
\hline \multicolumn{4}{|c|}{ Commercial } & \multicolumn{4}{|c|}{ Medicare Advantage } & \multicolumn{4}{|c|}{ Medicare FFS } \\
\hline \multicolumn{2}{|c|}{$\begin{array}{l}\text { Change from } \\
\text { baseline to Period } 1\end{array}$} & \multicolumn{2}{|c|}{$\begin{array}{l}\text { Change from Period } \\
1 \text { to } 2\end{array}$} & \multicolumn{2}{|c|}{$\begin{array}{l}\text { Change from baseline } \\
\text { to Period } 1\end{array}$} & \multicolumn{2}{|c|}{$\begin{array}{l}\text { Change from Period } 1 \\
\text { to } 2\end{array}$} & \multicolumn{2}{|c|}{$\begin{array}{l}\text { Change from baseline } \\
\text { to Period } 1\end{array}$} & \multicolumn{2}{|c|}{$\begin{array}{l}\text { Change from Period } 1 \\
\text { to } 2\end{array}$} \\
\hline Trends & Levels & Trends & Levels & Trends & Levels & Trends & Levels & Trends & Levels & Trends & Levels \\
\hline (1) & (2) & (3) & (4) & (5) & (6) & (7) & (8) & (9) & (10) & (11) & (12) \\
\hline
\end{tabular}

Panel A: Nephrologists relative to PCPs (reference)

$\begin{array}{clllll}\text { Difference } & -0.19 & 1.40 & 0.16 & 0.17 & -0.12 \\ & (-0.42, & (-1.38, & (-2.41, & (-2.41, & (-0.27, \\ 0.03) & 4.18) & 2.75) & 2.75) & 0.04) \\ {[0.085]} & {[0.323]} & {[0.101]} & {[0.896]} & {[0.145]}\end{array}$

$\begin{array}{lll}-0.58 & 0.15 & -0.63 \\ (-2.57,1.40) & (0.02,0.28) & (-2.26 \\ & 1.00) \\ {[0.565]} & {[0.024]} & {[0.447]}\end{array}$

-0.01
$(-0.05$
$0.03)$
$[0.601]$

0.09
$(-0.51$
$0.33)$
$[0.661]$

0.04

$-0.13$

Panel B: Female physicians relative to male physicians (reference)

Difference -0.08

$\begin{array}{lll}-0.80 & 0.09 & 0.50 \\ (-3.38, & (-0.09, & (-1.96 \\ 1.78) & 0.28) & 2.96) \\ {[0.543]} & {[0.324]} & {[0.691]}\end{array}$

0.24

$2.11-0.06$

$\begin{array}{ll}(-0.29, & (-3.38, \\ 0.14) & 1.78) \\ {[0.480]} & {[0.543]}\end{array}$

[0.324]

[0.691]

$(0.04,0.44) \quad(-0.31,4.54) \quad(-0.21$

[0.017]

[0.088]

[0.432]

0.03
$(-1.93$
$1.99)$
$[0.974]$

$(-0.06$

$0.02)$

[0.326]

$$
\begin{aligned}
& -0.19 \\
& (-0.60 \\
& 0.23)
\end{aligned}
$$

[0.373]

$(0.01,0.07)$

[0.020]

$(-0.55$,

\begin{tabular}{|c|c|c|c|c|c|c|c|c|c|c|c|c|}
\hline \multirow[t]{2}{*}{ Difference } & 0.00 & 0.75 & 0.05 & 0.34 & 0.06 & -2.04 & -0.11 & -0.81 & -0.02 & 0.08 & 0.03 & 0.19 \\
\hline & $\begin{array}{l}(-0.17 \\
0.17)\end{array}$ & $\begin{array}{l}(-1.20 \\
2.70)\end{array}$ & $\begin{array}{l}(-0.10, \\
0.20)\end{array}$ & $\begin{array}{l}(-1.58, \\
2.25)\end{array}$ & $\begin{array}{l}(-0.09 \\
0.21)\end{array}$ & $\begin{array}{l}(-3.95,- \\
0.12)\end{array}$ & $\begin{array}{l}(-0.23 \\
0.01)\end{array}$ & $\begin{array}{l}(-2.38 \\
0.75)\end{array}$ & $\begin{array}{l}(-0.04 \\
0.01)\end{array}$ & $\begin{array}{l}(-0.23 \\
0.40)\end{array}$ & $(0.003,0.05)$ & $\begin{array}{l}(-0.11, \\
0.49)\end{array}$ \\
\hline
\end{tabular}

$0.29)$

Panel C: Physicians under 50 years old relative to physicians over 50 years old (reference)

Estimates are reported for changes of trends and levels of EPO use (compared to previous periods) by physician's characteristics as well as P-value for differences across physician characteristics. Baseline refers to the period between Jan-2007 to June-2009; period 1 (post-TREAT/pre-FDA) is between Feb-2010 and Feb-2011; period 2 (post-TREAT/post-FDA) is between Oct-2011 and Dec-2015. All estimates were multiplied with 100 to represent percentage point changes. All samples consist of patients with CKD stage 3 to 5 . All models control for patients' sex and age and physicians' specialty, age, sex, and experience (see text for details). Standard errors are clustered at the patient level; $95 \%$ confidence interval is reported in parentheses, and $P$-value is reported in brackets

50 years old in the commercial group. In the MA group, physicians under 50 years old exhibited a larger immediate decrease in EPO prescribing following the trial publication ( $P$-value $<0.05)$. In the Medicare FFS group, physicians under 50 years old also had a larger increase in monthly EPO trends $(P$-value $<0.05)$ after the FDA revision.

\section{Discussion}

In this examination of ESA use in three insurance cohorts, we found that DPO and EPO use were both already declining prior to the TREAT trial publication, and they continued to decrease following the TREAT trial and the FDA black box warning revision. While this was consistent with prior research, we also found differences in how the trends and levels changed: by treatment, by insurance group, and by physician characteristics. Consistent with expectations, the decline in EPO use became steeper after the TREAT trial across all three insurance groups, but surprisingly, the decline in DPO use slowed (the trend was less negative) after the TREAT trial in commercially insured and Medicare FFS groups and did not change in the MA group. One critique of the trial is that more patients from the placebo group received intravenous iron than patients assigned to darbepoetin alfa due to a lack of an iron administration protocol; this limitation might have led to skepticism from physicians and a lack of response to the evidence of the trial [15]. Moreover, after the FDA revision, the decline in DPO use slowed again in the MA and Medicare FFS, though not in the commercial group, while the decline in EPO use slowed in all three groups.

Notably, although the decline in DPO prescribing slowed after both the TREAT trial and the FDA revision, DPO use dropped immediately after the FDA revision in all three insurance groups; this suggests both that the subsequent weaker decline (relative to the trend prior to the FDA revision) may reflect in part lower overall use, and also that the FDA revision was viewed as stronger evidence relative to the TREAT trial publication associated with a decrease in use. We observed the similar immediate decline for EPO use after the FDA revision as well.

Differences in de-adoption across insurance cohorts were minor and with no consistent relationship between insurance group and changes in levels or trends. That we found fewer changes in levels and trends in the commercial cohort may reflect the smaller sample size, especially compared with the FFS group (with 34 times as many patients), but even that cohort had more than half a million patients. More likely these differences reflect differences in providers who treat more or fewer commercial, FFS or MA patients.

With regards to providers, we found that both the slower decline trend in DPO use as well as the faster decline trend in EPO use after the TREAT trial were generally driven by nephrologists to a greater extent. We also observed some differences in responses to the trial 
and the warning revision by physician's gender and age, but the differences were not consistent for DPO and EPO and for different insurance populations. These results suggest that physician specialty have a dominant role in prescribing decisions, and that specializations with higher use of treatments were more responsive to new evidence of unsafety and ineffectiveness. This may be because the patient populations attributed to specialists for a given condition, in this case nephrologists, were more severe in unobserved ways.

Our findings are broadly consistent with prior research on de-adoption of treatments, which has found variation across providers in how rapidly treatments fall out of use in the wake of new evidence. Borne et al. [37] found that variation across institutions increased with increasing de-adoption of defibrillation following evidence of risk, indicating that providers de-adopted at different rates; they attribute this to different institutional practices. Bekelis et al. [38] found that more experienced physicians reduced their use of carotid revascularization more quickly than other physicians, while higher volume physicians reduced their use more slowly. More generally, van Dulmen et al. [39] identified 263 barriers to deadoption of treatments, of which the majority were physician factors. Thus, there are large variety of factors that may systematically influence the de-adoption of EPO and DPO, which suggests the need for systematic efforts to promote de-adoption [40].

There are several limitations to this study. First, our patient populations were identified using diagnosis codes and medication use in administrative claims. It also only included patients with non-dialysis CKD stages 3 to 5 , so our results may not be generalized to other types of patients. Moreover, our analyses could not account for many unobserved factors of ESA use such as treatment cost, patient preference, and ESA treatment appropriateness. The FDA warning indicated that ESA treatment can be considered if the hemoglobin level was less than $10 \mathrm{~g} / \mathrm{dL}$, the rate of hemoglobin declined, and reducing the risk of alloimmunization and/or red blood cell transfusion was the goal. These unobserved conditions would influence physician decisions whether to prescribe ESA treatment for patients.

Our data did not cover the period before 2007 so our analyses could not account for earlier studies on the unsafety of ESA treatment, including the NHCT, CHOIR, and CREATE trials, although other studies found that ESA prescribing trends substantially decreased in 2007 as a response to these events [18, 19]. However, we note that our segmented regression approach controls for monthly trends and levels of ESA use between January 2007 and the TREAT trial publication in 2009. Although there are other events that also influenced ESA prescribing decisions such as the
Medicare reimbursement reform in 2011 and the peritoneal dialysis solution shortage in 2014 [22, 23, 41], they mainly concerned patients on dialysis, who were not part of our study populations; therefore, we do not expect our results to be affected by these events. Lastly, it is possible that physicians also changed ESA dosage in response to the FDA warning; however, we did not assess changes in ESA dosage because our analysis was conducted at the patient-month level, while an adequate dosing is usually measured over consecutive days or weeks of therapy for a patient, depending on the half-life of the drug.

In summary, we found that DPO and EPO prescribing started decreasing in 2007 and continued to decline over the study period. The impact of the TREAT trial and of the FDA revision was limited and inconsistent, with a de-adoption rates of decline slowing for DPO for some payers. These findings have implications for the treatment of CKD both inside and outside of the US, as ESA continues to be the most common therapy to treat anemia among CKD patients [7].

Our study is also relevant to a growing literature on physicians' decisions to de-adopt treatments in light of new clinical evidence suggesting that a previously-approved treatment is ineffective or unsafe [37-40, 42-44]. While existing studies mostly focus on measuring the rate of de-adoption or reductions in prescribing, there is less evidence regarding variation in de-adoption $[38,44]$. Our findings indicate that deadoption of unsafe treatments varies across insurance types and across physician specialties and characteristics. It is important to take these variations into account when designing practice guidance to promote efficient de-adoption.

\section{Abbreviations}

ESA: Erythropoiesis-stimulating agents; CKD: Chronic kidney Disease; EPO: Epoetin alfa; DPO: Darbepoetin alfa; TREAT: Trial to Reduce Cardiovascular Events with Aranesp Therapy; FDA: Food and Drug Administration; MA: Medicare Advantage; FFS: Fee-for-Service; OLDW: OptumLabs ${ }^{\oplus}$ Data Warehouse; E\&M: Evaluation and management; NPI: National Physician Identification; PCP: Primary care physicians; SD: Standard deviation

\section{Supplementary Information}

The online version contains supplementary material available at https://doi. org/10.1186/s12882-021-02491-y.

\section{Additional file 1}

\section{Acknowledgements}

Not applicable.

Authors' contributions

PKM, JH, ND, JR, AJ, NS conceptualized the study design. PKM acquired the data; KV and JZ analyzed the data; KV and JZ prepared the tables and figures; KV, PKM, AE, JZ drafted and revised the paper; all authors participated in interpretation of the data, provided critical review, and approved the final version of the manuscript. 


\section{Funding}

Analyses were supported by funding from the National Heart, Lung, and Blood Institute (R56 HL130496, PI Karaca-Mandic) the Agency for Healthcare Research and Quality (R01 HS025164, PI Karaca-Mandic), and National Institute on Aging (P01AG005842, Pl of pilot grant Karaca-Mandic). These funding sources had no role in the design and conduct of the study, analysis or interpretation of the data; and preparation or final approval of the manuscript prior to publication.

\section{Availability of data and materials}

We are using proprietary data accessed from OptumLabs approved a Detailed Research Application (DRA) and administrative Medicare files from CMS that are approved under a Data Use Agreement (DUA) purchased from CMS for this project. Ass such we are not authorized to share any data, but we are happy to suggest researchers interested the appropriate steps to acquire data on their own for their specific DUA.

\section{Declarations}

\section{Ethics approval and consent to participate}

The study was deemed exempt from review by the University of Minnesota Institutional Review Board because the data were de-identified.

\section{Consent for publication}

Not applicable.

\section{Competing interests}

In the past 36 months, Alexander Everhart has worked as a graduate research fellow at Medtronic plc. Nihar Desai reports grants and personal fees from Amgen, grants and personal fees from Boehringer Ingelheim, grants and personal fees from Cytokinetics, personal fees from Novartis, grants and personal fees from Relypsa, and personal fees from SC Pharmaceuticals. Jeph Herrin reports grants from the Agency for Healthcare Research and Quality. Anupam Jena reports grants from the National Institutes of Health, personal fees from Pfizer, personal fees from Hill Rom Services, Inc., personal fees from Bristol Myers Squibb, personal fees from Novartis Pharmaceuticals, personal fees from Vertex Pharmaceuticals, personal fees from Precision Health Economics, personal fees from Amgen, personal fees from Eli Lilly, personal fees from Analysis Group, personal fees from Sanofi Aventis, personal fees from Celgene, personal fees from Tesaro, personal fees from AstraZeneca, and personal fees from Biogen. Joseph Ross reports grants from the Food and Drug Administration, grants from Medtronic plc, grants from Johnson \& Johnson, grants from the Centers for Medicare and Medicaid Services, grants from Blue Cross-Blue Shield Association, grants from the Agency for Healthcare Research and Quality, grants from Laura and John Arnold Foundation, grants from the National Institutes of Health - National Heart Lung, and Blood Institute, grants from the Laura and John Arnold Foundation, and grants from the Medical Devices Innovation Consortium. Dr. Shah has received research support through Mayo Clinic from the Food and Drug Administration, the Centers of Medicare and Medicaid Services, Agency for Healthcare Research and Quality, National Science Foundation, and PCORI. Dr. Karaca Mandic reports grants from the Agency for Healthcare Research and Quality, grants from the National Institutes of Health - National Heart, Lung, and Blood Institute, grants from the American Cancer Society, personal fees from Tactile Medical, Precision Health Economics and Sempre Health for work unrelated to this project.

\footnotetext{
Author details

'Department of Applied Economics, University of Minnesota, 1994 Buford Avenue, St. Paul, MN 55108, USA. ${ }^{2}$ University of Minnesota School of Public Health, 420 Delaware St. SE, Minneapolis, MN 55455, USA. ${ }^{3}$ Cardiovascular Medicine, Yale School of Medicine, 15 York Street, PO Box 208017, New Haven, CT 06520-8017, USA. ${ }^{4}$ Yale School of Medicine, PO Box 2254, Charlottesville, Virginia 22902, USA. ${ }^{5}$ Harvard Medical School and National Bureau of Economic Research, 180 Longwood Avenue, Boston, MA 02115, USA. ${ }^{6}$ Yale School of Medicine, General Internal Medicine, P.O. Box 208093, New Haven, CT 06520-8093, USA. ${ }^{7}$ Mayo Clinic, Rochester, MN 55905, USA. ${ }^{8}$ National Bureau of Economic Research and OptumLabs Visiting Fellow, University of Minnesota Carlson School of Management, 321 19th Avenue South, Minneapolis, MN 55455, USA.
}

Received: 2 March 2021 Accepted: 3 August 2021

Published online: 21 August 2021

\section{References}

1. U.S. Food and Drug Administration. Information on ErythropoiesisStimulating Agents (ESA) EPOETIN alfa (marketed as Procrit, Epogen), DARBEPOETIN alfa (marketed as Aranesp). https://www.fda.gov/drugs/ postmarket-drug-safety-information-patients-and-providers/informationerythropoiesis-stimulating-agents-esa-epoetin-alfa-marketed-procrit-epogendarbepoetin. Accessed 15 Aug 2021.

2. Founation NK. II. Clinical practice guidelines and clinical practice recommendations for Anemia in Chronic Kidney disease in adults. Am J Kidney Dis. 2006;47:S16. https://doi.org/10.1053/j.ajkd.2006.03.011.

3. U.S. Food and Drug Administration. Information for Aranesp (darbepoetin alfa). https://www.fda.gov/drugs/postmarket-drug-safety-information-pa tients-and-providers/information-aranesp-darbepoetin-alfa. Accessed 16 Aug 2021.

4. Palmer SC, Saglimbene V, Mavridis D, Salanti G, Craig JC, Tonelli M, et al. Erythropoiesis-stimulating agents for anaemia in adults with chronic kidney disease: a network meta-analysis. Cochrane Database Syst Rev. 2014;12. https://doi.org/10.1002/14651858.CD010590.pub2.

5. Carrera F, Burnier M. Use of darbepoetin alfa in the treatment of anaemia of chronic kidney disease: clinical and pharmacoeconomic considerations. NDT Plus. 2009;2(suppl_1):i9-i17. https://doi.org/10.1093/ndtplus/sfn175.

6. Kliger AS, Foley RN, Goldfarb DS, Goldstein SL, Johansen K, Singh A, et al. KDOQI US commentary on the $2012 \mathrm{KDIGO}$ clinical practice guideline for Anemia in CKD. Am J Kidney Dis. 2013;62(5):849-59. https://doi.org/10.1053/ j.ajkd.2013.06.008

7. Wong MMY, Tu C, Li Y, Perlman RL, Pecoits-Filho R, Lopes AA, et al. Anemia and iron deficiency among chronic kidney disease stages 3-5ND patients in the chronic kidney disease outcomes and practice patterns study: often unmeasured, variably treated. Clin Kidney J. 2020;13(4):613-24. https://doi. org/10.1093/ckj/sfz091.

8. Besarab A, Bolton WK, Browne JK, Egrie JC, Nissenson AR, Okamoto DM, et al. The effects of Normal as compared with low hematocrit values in patients with cardiac disease who are receiving hemodialysis and Epoetin. N Engl J Med. 1998;339(9):584-90. https://doi.org/10.1056/NEJM1998082733 90903.

9. Singh AK, Szczech L, Tang KL, Barnhart H, Sapp S, Wolfson M, et al. Correction of Anemia with Epoetin alfa in chronic kidney disease. N Engl J Med. 2006;355(20):2085-98. https://doi.org/10.1056/NEJMoa065485.

10. Drüeke TB, Locatelli F, Clyne N, Eckardt K-U, Macdougall IC, Tsakiris D, et al. Normalization of hemoglobin level in patients with chronic kidney disease and Anemia. N Engl J Med. 2006;355(20):2071-84. https://doi.org/10.1056/ NEJMoa062276.

11. Pfeffer MA, Burdmann EA, Chen C-Y, Cooper ME, de Zeeuw D, Eckardt K-U, et al. A trial of Darbepoetin alfa in type 2 diabetes and chronic kidney disease. N Engl J Med. 2009;361(21):2019-32. https://doi.org/10.1056/ NEJMoa0907845.

12. U.S. Food and Drug Administration. FDA drug safety communication: modified dosing recommendations to improve the safe use of erythropoiesis-stimulating agents (ESAs) in chronic kidney disease. 2011.

13. KDOQI. Clinical practice guidelines and clinical practice recommendations for Anemia in Chronic Kidney Disease. Am J Kidney Dis. 2006;47:S1-S146.

14. Locatelli F, Covic A, Eckardt KU, et al. ERA-EDTA ERBP Advisory Board. Anaemia management in patients with chronic kidney disease: a position statement by the Anaemia Working Group of European Renal Best Practice (ERBP). Nephrol Dial Transplant. 2009;24:348-54.

15. Locatelli F, Aljama P, Canaud B, Covic A, De Francisco A, Macdougall IC, et al. Target haemoglobin to aim for with erythropoiesis-stimulating agents: a position statement by ERBP following publication of the trial to reduce cardiovascular events with Aranesp therapy (TREAT) study. Nephrol Dial Transpl. 2010;25(9):2846-50. https://doi.org/10.1093/ndt/gfq336.

16. Yamamoto H, Nishi S, Tomo T, Masakane I, Saito K, Nangaku M, et al. 2015 Japanese Society for Dialysis Therapy: guidelines for renal Anemia in chronic kidney disease. Renal Replace Ther. 2017;3(1):36. https://doi.org/10.1186/ s41100-017-0114-y.

17. Fuller DS, Bieber BA, Pisoni RL, Li Y, Morgenstern H, Akizawa T, et al. International comparisons to assess effects of payment and regulatory changes in the United States on Anemia practice in patients on 
hemodialysis: the Dialysis outcomes and practice patterns study. J Am Soc Nephrol. 2016;27(7):2205 LP-2215. https://doi.org/10.1681/ASN.2015060673.

18. Regidor D, McClellan WM, Kewalramani R, Sharma A, Bradbury BD. Changes in erythropoiesis-stimulating agent (ESA) dosing and haemoglobin levels in US non-dialysis chronic kidney disease patients between 2005 and 2009. Nephrol Dial Transpl. 2011;26(5):1583-91. https://doi.org/10.1093/ndt/ gfa573.

19. Freburger JK, Ng LJ, Bradbury BD, Kshirsagar AV, Brookhart MA. Changing patterns of Anemia management in US hemodialysis patients. Am J Med. 2012;125(9):906-914.e9. https://doi.org/10.1016/j.amjmed.2012.03.011.

20. Thamer M, Zhang Y, Lai D, Kshirsagar O, Cotter D. Influence of safety warnings on ESA prescribing among dialysis patients using an interrupted time series. BMC Nephrol. 2013;14(1):172. https://doi.org/10.1186/1471-23 69-14-172.

21. Park H, Liu X, Henry L, Harman J, Ross EA. Trends in anemia care in nondialysis-dependent chronic kidney disease (CKD) patients in the United States (2006-2015). BMC Nephrol. 2018;19(1):318. https://doi.org/10.1186/s12 882-018-1119-7.

22. Swaminathan S, Mor V, Mehrotra R, Trivedi AN. Effect of Medicare Dialysis payment reform on use of erythropoiesis stimulating agents. Health Serv Res. 2015:50(3):790-808. https://doi.org/10.1111/1475-6773.12252.

23. Chertow GM, Liu J, Monda KL, Gilbertson DT, Brookhart MA, Beaubrun AC, et al. Epoetin alfa and outcomes in Dialysis amid regulatory and payment reform. J Am Soc Nephrol. 2016;27(10):3129 LP-3138. https://doi.org/10.1 681/ASN.2015111232.

24. Weir MA, Gomes T, Winquist E, Juurlink DN, Cuerden MS, Mamdani M. Effects of funding policy changes and health warnings on the use of erythropoiesis-stimulating agents. J Oncol Pract. 2012;8(3):179-83. https:// doi.org/10.1200/JOP.2011.000287.

25. Sakaguchi Y, Hamano T, Wada A, Masakane I. Types of erythropoietin-stimulating agents and mortality among patients undergoing hemodialysis. J Am Soc Nephrol. 2019:30(6):1037-48. https:/doi.org/10.1681/ASN.2018101007.

26. Jordan J, Breckles J, Leung V, Hopkins M, Battistella M. Conversion from epoetin alfa to darbepoetin alfa: effects on patients' hemoglobin and costs to Canadian dialysis centres. Can J Hosp Pharm. 2012;65(6):443-9. https:// doi.org/10.4212/cjhp.v65i6.1192.

27. Stauffer M, Fan T. Prevalence of anemia in chronic kidney disease in the United States. PLoS One. 2014;9(1):e84943.

28. OptumLabs. OptumLabs and OptumLabs Data Warehouse (OLDW) Descriptions and Citation. Eden Prairie, 2019. Reproduced with permission from OptumLabs.

29. Jena $A B$, Khullar $D$, Ho O, Olenski AR, Blumenthal DM. Sex differences in academic rank in US medical schools in 2014. JAMA. 2015;314(11):1149-58. https://doi.org/10.1001/jama.2015.10680.

30. Jena $A B$, Olenski AR, Blumenthal DM. Sex differences in physician salary in US public medical schools. JAMA Intern Med. 2016;176(9):1294-304. https:// doi.org/10.1001/jamainternmed.2016.3284

31. Tsugawa Y, Blumenthal DM, Jha AK, Orav EJ, Jena AB. Association between physician \&lt;em\&gt;US News \&amp;amp; World Report\&lt;/em\&gt; medical school ranking and patient outcomes and costs of care: observational study. BMJ. 2018;362:k3640. https://doi.org/10.1136/bmj.k3640.

32. Smith LB, Desai NR, Dowd B, et al. Patient and provider-level factors associated with changes in utilization of treatments in response to evidence on ineffectiveness or harm. Int J Health Econ Manag. 2020;(3):299-317. https://doi.org/10.1007/s10754-020-09282-2.

33. Siegel J, Jorgenson J, Johnson PE, Brophy DF, Comstock T, Feng A, et al. Use and prescribing patterns for erythropoiesis-stimulating agents in inpatient and outpatient hospital settings. Am J Health Pharm. 2008;65(18): 1711-9. https://doi.org/10.2146/ajhp070526.

34. Kontopantelis E, Doran T, Springate DA, Buchan I, Reeves D. Regression based quasi-experimental approach when randomisation is not an option: interrupted time series analysis. BMJ. 2015;350(jun09 5):h2750. https://doi. org/10.1136/bmj.h2750.

35. Penfold RB, Zhang F. Use of interrupted time series analysis in evaluating health care quality improvements. Acad Pediatr. 2013;13(6):S38-44. https:// doi.org/10.1016/j.acap.2013.08.002.

36. Wagner AK, Soumerai SB, Zhang F, Ross-Degnan D. Segmented regression analysis of interrupted time series studies in medication use research. J Clin Pharm Ther. 2002;27(4):299-309. https://doi.org/10.1046/j.1365-2710.2002. 00430.x.
37. Borne RT, Randolph T, Wang Y, Curtis JP, Peterson PN, Masoudi FA, et al. Analysis of temporal trends and variation in the use of defibrillation testing in contemporary practice. JAMA Netw Open. 2019;2(10):e1913553. https:// doi.org/10.1001/jamanetworkopen.2019.13553.

38. Bekelis K, Skinner J, Gottlieb D, Goodney P. De-adoption and exnovation in the use of carotid revascularization: retrospective cohort study. BMJ. 2017: 359:j4695. https://doi.org/10.1136/bmj.j4695.

39. van Dulmen SA, Naaktgeboren CA, Heus P, Verkerk EW, Weenink J, Kool RB, et al. Barriers and facilitators to reduce low-value care: a qualitative evidence synthesis. BMJ Open. 2020;10(10):e040025. https://doi.org/10.1136/ bmjopen-2020-040025.

40. Selby K, Barnes GD. Learning to De-adopt ineffective healthcare practices. Am J Med. 2018;131(7):721-2. https://doi.org/10.1016/.amjmed.2018.03.014.

41. Jensen V, Throckmorton DC. Shortage of peritoneal Dialysis solution and the Food and Drug Administration's response. Clin J Am Soc Nephrol. 2015; 10(8):1484-6. https://doi.org/10.2215/CJN.12061214.

42. Prasad V, Gall V, Cifu A. The frequency of medical reversal. Arch Intern Med. 2011;171(18):1675-6. https://doi.org/10.1001/archinternmed.2011.295.

43. Roman BR, Asch DA. Faded promises: the challenge of deadopting lowvalue care. Ann Intern Med. 2014;161(2):149-50. https://doi.org/10.7326/ M14-0212.

44. Niven DJ, Mrklas KJ, Holodinsky JK, Straus SE, Hemmelgarn BR, Jeffs LP, et al. Towards understanding the de-adoption of low-value clinical practices: a scoping review. BMC Med. 2015;13(1):255. https://doi.org/10.1186/s12916-01 5-0488-z.

\section{Publisher's Note}

Springer Nature remains neutral with regard to jurisdictional claims in published maps and institutional affiliations.
Ready to submit your research? Choose BMC and benefit from:

- fast, convenient online submission

- thorough peer review by experienced researchers in your field

- rapid publication on acceptance

- support for research data, including large and complex data types

- gold Open Access which fosters wider collaboration and increased citations

- maximum visibility for your research: over $100 \mathrm{M}$ website views per year

At BMC, research is always in progress.

Learn more biomedcentral.com/submissions 